Print ISSN: 2233-4165 / Online ISSN 2233-5382

doi:http://dx.doi.org/10.13106/jidb.2020.vol11.no4.39

\title{
The Relationship between Discretionary Revenues and Book-Tax Difference
}

\author{
Sangkwon CHA*, Jiyeon YOO**
}

Received: March 07, 2020 Revised: March 17, 2020 Accepted: April 05, 2020.

\begin{abstract}
Purpose: This study looks at the relevance between discretionary revenue and book-tax differences (hereafter BTDs). While the study of earnings management, which focused on discretionary accruals and real earnings management, has largely made, it has not yet been actively researched on discretionary revenues. Therefore, it was believed that discretionary revenue would expand the preceding study by looking at its relevance to BTD, known as financial reporting quality and measures of tax avoidance. In general, prior research suggested that earnings management make BTDs larger. Thus, the relationship between discretionary revenue and the amount of BTD is predicted positive. Research design, data and methodology: To this end, the method of discretionary revenues was used and BTDs measured in four ways. First, Earnings before income tax estimated taxable income divided by total asset (BTD). Second is fractional rank variable of BTDs (FBTD). Third is Indicator variable equals 1 if the firm-year has a positive BTD, 0 otherwise (PBTD). Fourth is that Indicator variable equals 1 if the firm-year has a BTDs in top(bottom) quartile, 0 otherwise (LPBTD, LNBTD). 4,251 samples were analyzed in the Korean Security market (KOSPI) from 2003 to 2014 . Results Empirical analysis shows that BTDs increases as discretionary revenue increases. These results were equally observed when BTDs was measured as a ranking variable or as a indicating variable. These results indicate that earnings management through the revenue of managers exacerbate the quality of financial reporting. Conclusions: In sum, discretionary revenues can be used as an indicator of making BTDs larger and meaningful as the first study of the Korean capital market where discretionary revenues affect accounting information quality. Investors need to increase interest in discretionary revenues because intervention in financial reporting through revenue accounts by managers can increase information asymmetry and agency costs. This means that studies on discretionary revenues that have been relatively small should be expanded. The results also provide important implications for the relevant authorities and investors. Despite these benefits, however, measurement error problems with estimates still appear as limited points, and prudent interpretations are required, and additional follow-up studies are needed in that variables that are not yet considered in this study may affect our findings.
\end{abstract}

Keywords : Discretionary Revenues, Earnings Management, Book-Tax Difference, Financial Reporting Quality

JEL Classification Code : M11, M40, M41

\section{1. 서론}

본 연구는 그간의 회계학 연구에서 다루어 온 경영자의 재무보고 개입과 회계이익과 과세소득의 차이(이하 BTD)간의 관련성을 확장하여

*First Author and Corresponding Author: Ph.D. Candidate, The Department of Accounting, Hanyang University, Seoul, Korea, Email: sangkwon@hanyang.ac.kr

${ }^{*}$ Co Author: Assistant Professor, The Department of Accounting, Sangji University, Seoul, Korea, Email: wldus1005@daum.net $\odot$ Copyright: Korean Distribution Science Association (KODISA)

This is an Open Access article distributed under the terms of the Creative Commons Atribution NonCommercial License (https:///reativecommons.orglicenses/by-nc/4.0/) which permits unrestricted non-
기업의 수익을 통한 이익조정이 BTD 에 미치는 영향을 살펴보는 것을 목적으로 한다. 회계학 연구에서 주로 이용되어온 이익조정의 측정은 Jones(1991)의 연구방법론이나 이를 변형한 Dechow, Sloan and Sweeny(1995), 및 Kothari, Leone and Wasley(2005)에서 제안한 발생액을 통한 이익조정에 관심을 가지고 연구를 진행해왔다. 그러나 재량적 발생액이 갖는 추정오차 문제와 재량적 발생액이 이익조정을 측정하는지에 관한 타당성의 문제를 가지고 있었다. 따라서 후속연구에서는 이를 보완하기 위해 다양한 측정방법을 이용한 실증적 증거를 제시하였다. 예컨대 Roychowdhury(2006)의 실제 활동을 통한 이익조정이나 Dechow and Dichev(2002)의 발생액의 질과 같은 방법이 
고안도출되었고 이후 후속연구에서는 이러한 방법들의 타당성 확보하고자 선행연구를 재검증하는 연구가 진행되었다. 본 연구는 상대적으로 최근에 제안된 재량적 수익조정을 경영자의 이익조정의 측정치로 이용하고 BTD 에 미치는 영향을 검증하고자 한다Stubben, 2010). 2003 년부터 2014 년까지의 표본기간을 대상으로 실증 분석한 결과 재량적 수익조정이 증가할수록 BTD 가 증가하는 양(+)의 관련성이 나타났다. 이러한 연구결과는 BTD 를 소수의 순위변수로 측정하거나, 지시변수로 측정한 경우에도 동일하게 나타났으며, 추가분석에서 $\mathrm{BTD}$ 를 4분위한 후, 가장 큰 양(+)의 BTD(PBTD)에 미치는 영향을 검증한 결과에서도 동일하게 나타났다. 본 연구의 결과는 국내자본시장을 대상으로 한 재량적 수익조정이 BTD 에 미치는 영향이 존재한다는 실증적 결과를 제시하는 최초의 연구로써 의의를 가지며, 이는 선행연구를 확장 및 보완하는 증거를 제시한다는 점에서 공헌점이 존재한다. 한편, 본 연구의 구성은 다음과 같다. 제 2 장에서는 재량적 수익조정에 관한 선행연구와 BTD 에 관한 이론적 배경을 검토 후 가설을 도출하고 제 3 장에서는 가설을 검증하는 연구방법을 연구모형, 변수정의 및 표본선정의 순으로 기술하였다. 제 4 장 실증분석결과에서는 제 3 장의 연구방법론을 바탕으로 실시한 검증결과를 표와 함께 기술하였으며 마지막으로 제 5 장에는 본 연구의 결론과 한계점 및 시사점을 제시하였다.

\section{2. 선행연구 및 가설 설정}

회계학 연구에서 널리 이용된 이익조정의 측정치인 재량적 발생액은 다수의 문헌연구 및 실증연구에 의해 그 한계점이 많이 제시되었다. 그러한 연구에서는 비판적 관점에서의 논문과 함께 한계점을 보완하는 연구들도 많이 제시되어 왔다. 특히, 한계점을 보완하는 측정치로 제시된 대표적인 경우는 Dechow et al.(1995)나 Kothan et al.(2005)의 연구를 들 수 있다. 두 연구에서는 이익조정을 측정하는 재량적 발생액이 이익조정을 포착하지 못하거나 간과하는 문제점을 지적하였다. 이러한 문제점을 완화할 수 있는 방법으로 Stubben(2010)에서는 단일 구성 요소를 모형을 설정하면 측정 오류가 줄어 들 수 있음을 주장하면서 이익조정을 수익의 측면에서 바라본다면 비용항목을 통한 또는 자산항목을 통한 이익조정에서 수익 조정 대한 관점으로의 이익조정 폭을 확대할 수 있다고 보았다. 왜냐하면 대부분의 기업에서 재무보고 개입이 큰 항목은 수익항목이며, 재량에 따라 결정되는 이상적인 구성 요소이기 때문이라고 주장하였다. 이와 같은 맥락으로 Dechow and Schrand(2004)의 연구에 따르면 수익은 재무보고에서 가장 많은 오류가 존재하는 항목이며 Tumer et al.2001) 역시 수익은 가장 재무제표 재작성이 많이 되는 항목으로 보았다. 그러나 이를 이용한 실증연구결과는 상대적으로 미진한 실정이다.
한편, Lev \& Nissim(2004)은 BTD 는 이익조정을 포착하거나 세무이익의 핵심을 잘 나타내는 지표라고 주장하였다. Blaylock, Shevin \& Wilson(2011) 에서는 이러한 BTD 가 이익 지속성 (eamings persistence)에 영향을 미친다고 주장하였다. 이익의 지속성은 예측가치(predict value)를 내포하는 가장 직접적인 회계정보 품질을 측정하는 지표로써 BTD 가 이익지속성과의 어떠한(certain) 관계를 보인다는 것은 결국, BTD 가 재무보고 품질과 직접적인 관련이 존재함을 의미한다Plesko, 2007).

$\mathrm{BTD}$ 에 관한 선행연구에서 공통적으로 주장하는 것은 $\mathrm{BTD}$ 는 이익조정과 관련성이 있다는 것이다. Jadson(2015)의 연구에서 또한 $\mathrm{BTD}$ 의 구성 요소와 이익의 변동 사이의 연관성이 이익조정이 큰 기업에서 더 커진다고 주장하였으나 BTD와 이익의 변동성 간의 관계는 이익조정의 측정방식에 차이가 크다고 언급하였다. 이에 대한 BTD 에 관한 연구결과가 일반화를 위해서는 지속적으로 검증하는 것이 필요하다는 것을 의미한다.

국내자본시장을 대상으로 한 연구에서는 이전 연구에서는 주로 BTD 에 미치는 영향을 밝히기 위한 기업지배구조(Hwang, 2012; Lee, Ji, \& Ry, 2014), 감사품질(Park \& Jeon, 2008), 산업집중도(Cha \& Jin, 2017) 등을 고려한 경우이거나 BTD 가 회계정보 품질Yoo, 2011; Cho, Choi, \& Lee, 2011; Park Ki, \& Kwon, 2014; Cha \& Choi, 2017)에 미치는 영향을 고려한 연구결과를 제시하였다. 본 연구는 후자에 속하는 연구의 확장 형태인 것이다. 본 연구에서 관심변수로 삼는 재량적 수익조정의 측정치가 BTD 에 미치는 영향이 존재하지 않는다면 재량적 수익조정의 측정치가 이익조정을 포착하지 못하는 것이며, 재량적 수익조정의 측정치와 BTD 간의 유의한 양(+)의 관계가 나타난다면 수익항목을 통한 이익조정이 나타남을 밝히게 된다. 아울러 재량적 수익조정이 국내 자본시장에서도 유용한 지표로서 가능성을 탐색할 수 있는 연구임에 의의가 존재한다. 대체적으로 선행연구에서는 경영자의 이익조정이 BTD 를 크게 만든다고 주장하였다(Desai \& Dhamapala, 2009; Tang \& Firth, 2011). 따라서 재량적 수익과 BTD 간의 양의 관련성이 예측되는 바, 이에 다음과 같이 가설을 설정하였다.

연구가설: 재량적 수익이 커질수록 BTD 는 증가할 것이다.

\section{3. 연구방법론}

\section{1. 연구모형}

본 연구의 가설을 검증하기 위한 모형은 선행연구를 참조하여 다음과 같이 설정하였대Chun \& Shim, 2017; Aż, Ji, \& Lee, 2019; Cha \& Choi, 2020). 연구모형에서 아래 첨자 $i$ 는 기업을, $\mathrm{t}$ 는 시점을 가리키며 변수의 조작적 정의는 <Table 1>과 같다 


$$
\begin{aligned}
B T D_{i, t+1}= & \beta_{0}+\beta_{1} D R E V_{i, t}+\beta_{2} \text { SIZE }_{i, t}+\beta_{3} L E V_{i, t}+ \\
& \beta_{4} R O A_{i, t}+\beta_{5} B T M_{i, t}+\beta_{6} C A P E X_{i, t}+ \\
& \beta_{7} R S R V_{i, t}+\beta_{8} B E T A_{i, t}+\beta_{9} V O L_{i, t}+ \\
& \beta_{10} F O R_{i, t}+\beta_{11} B I G 4_{i, t}+\beta_{12} B E T A_{i, t}+ \\
& \sum Y E A R+\sum K S I C+\varepsilon_{i, t}
\end{aligned}
$$

Table 1: Variables Definition

\begin{tabular}{|ccc|}
\hline BTD & $:$ & Book-tax difference \\
\hline DREV & $:$ & Discretionary revenues \\
\hline SIZE & $:$ & Firm size \\
\hline LEV & $:$ & Leverage \\
\hline ROA & $:$ & Profitability \\
\hline BTM & $:$ & Market to book value \\
\hline CAPEX & $:$ & (tangible asset - land - construction in \\
progress)/total asset
\end{tabular}

종속변수의 구체적인 측정방법은 다음 절에 후술하였다. 종속변수가 연속변수인 경우(BTD, FBTD) 기업별, 연도별 군집성을 통제한 후의 OLS 를 실시하고(two-way dustening), 추가분석에서 실시한 종속변수인 BTD 가 지시변수인 경우(PBTD, LPBTD, LNBTD)에는 기업별, 연도별 군집성을 통제한 후의 logistic 회귀분석을 실시하였다. 위 식에서 $\beta_{1}$ 의 값이 유의한 양의 값을 갖는다면, 재량적 수익이 증가할수록 BTD 가 커진다는 것으로 본 연구의 가설을 지지하는 결과가 된다. 선행연구를 참조하여 BTD 에 영향을 미칠 것으로 기대되는 일정한 변수를 통제변수로 포함하였으며 고정효과를 통제하고자 산업별 지시변수와 연도별 지시변수를 모형에 포함하였다. 종속변수와 관심변수 간의 인과관계를 명확히 하고자 종속변수의 경우 $t+1$ 시점, 독립변수는 $\mathrm{t}$ 시점으로 측정하였다.

\section{2. 변수측정}

종속변수는 회계이익과 과세소득의 차이(BTD)다. 첫째, 회계이익은 법인세차감전순이익, 과세소득은 추정과세소득을 이용하였다. 여기서 추정과세소득은 기업의 법인세비용에 이연법인세자산 증감액을
가산하고 이연법인세부채 증감액을 차감한 값을 연도별 법인세율(연도별 최고세율을 이용하고 법인지방소득세를 포함)로 나누어 추정하였다(Oh \& Ki, 2020). 이렇게 계산된 회계이익과 과세소득의 차이를 자산총계로 나눈 값을 BTD 로 정의하였다. 두 번째로는 소수의 순위변수로 측정한 BTD 를 이용하였다. BTD를 단순히 연속변수의 BTD 뿐만 아니라 소수의 순위변수(fractional rank vaniables)로 치환하여 연구 결과의 일반화 가능성을 제고하고자 한다. 소수의 순위변수로 치환한 값을 이용하게 되면 연속변수를 이용할 때에 발생하는 극단 치에 의한 결과를 보다 완화할 수 있다고 알려져 있다(Park \& Yoon, 2014). 추가분석에서는 세 번째로 BTD 가 양(+)의 값을 가질 때 1 , 그렇지 않으면 0 의 값을 갖는 지시변수(PBTD)를 이용한다. $\mathrm{PBTD}$ 는 경영자의 상향이익조정여부를 판별하기 위한 변수이다(Park et al, 2014). 넷째, Crabtree and Maher(2009)의 연구방법론에 따라 큰 양(+)의 $\mathrm{BTD}(\mathrm{LBTD})$ 와 큰 음(-)의 BTD(LNBTD)를 이용하였다. 이를 요약하면 $<$ Table 2>와 같다.

Table 2: Variables Definition

\begin{tabular}{|l|l|}
\hline Variable & \multicolumn{1}{|c|}{ Operational Definition } \\
\hline BTD & $\begin{array}{l}\text { Earnings before income tax - estimated taxable inco } \\
\text { me/ total asset }\end{array}$ \\
\hline FBTD & Fraction rank variable of BTD \\
\hline PBTD & $\begin{array}{l}\text { Indicator variable equals 1 if the firm-year has a pos } \\
\text { itive BTD, 0 otherwise. }\end{array}$ \\
\hline LPBTD & $\begin{array}{l}\text { Indicator variable equals 1 if the firm-year has a BT } \\
\mathrm{D} \text { in top quartile, 0 otherwise }\end{array}$ \\
\hline LNBTD & $\begin{array}{l}\text { Indicator variable equals 1 if the firm-year has a BT } \\
\mathrm{D} \text { in bottom quartile, 0 otherwise }\end{array}$ \\
\hline
\end{tabular}

관심변수인 재량적 수익조정은 Stubben (2010)에서 제시한 재량적 수익조정(DREV)을 이용하고자 한다. 재량적 수익조정은 이익조정의 가장 일반적인 형태이며 재량적 수익조정의 측정은 재량적 발생액 측정보다 측정 오차 및 편차가 현저히 낮은 방법이다. 재량적 수익조정은 다음의 식을 산업-연도별로 추정한 값을 이용한다. 아래의 식의 하단에는 <Table 3>에 변수의 조작적 정의를 제시하였다. 한편, 재량적 수익을 추정할 때에 산업-연도별 표본의 크기가 20 이하인 경우는 표본에서 제외하였다.

$$
\Delta A R_{i, t}=\alpha_{0}+\alpha_{1} \frac{\Delta S A L E S_{i, q 1-q 3}}{\Delta A S S E T_{\text {ave }}}+\alpha_{2} \frac{\Delta S A L E S_{i, q 4}}{\Delta A S S E T_{\text {ave }}}+\varepsilon_{i, t}
$$

통제변수로는 선행연구에서 공통적으로 이용한 변수를 이용하였다 (Aziz et al. 2019). 기업규모(SZE)는 자산총계에 자연로그를 취한 값으로 기 업규모가 미치는 영향을 통제하고도 관심변수와 종속변수 간의 유의한 관계가 유지되는 확인하고자 포함하였다. 기업규모를 통제변수로 이용 
하면 본 연구에서 미처 고려하지 못한 변수의 영향을 통제할 수 있다고 알려져 있다(Becker, DeFond, \& Jiambalvo,1998). 부채비율(IIV)은 안정성과 관련된 기업특성을 통제하고자 본 연구에 포함하였다(Cha \& Park, 2020).

Table 3: Variables Definition

\begin{tabular}{|l|l|}
\hline$\triangle A \boldsymbol{R}_{i, t}$ & Accounting receivables growth \\
\hline$\triangle \boldsymbol{A S S E T _ { \text { ave } }}$ & Average total asset of $\mathrm{t}-1$ and $\mathrm{t}$ year \\
\hline$\Delta \boldsymbol{S A L E S _ { i , q 1 - q 3 }}$ & Sales changes from $1^{\text {st }}$ to $3^{\text {rd }}$ quarter \\
\hline$\Delta \boldsymbol{S A L E S _ { i , q 4 }}$ & Annual sales changes in the fourth quarter \\
\hline $\mathbf{E}$ & Residuals \\
\hline
\end{tabular}

수익성(ROA)은 당기순이익을 자산총계로 나눈 값을 이용하였다. BT $\mathrm{M}$ 은 장부가치 대비 시장가치의 비중으로 기업 가치 또는 성장성을 대 리하는 변수로 이용되는 변수이다. 따라서 BTM은 종속변수(BTD)와 양 $(+)$ 의 관련성이 사전적으로 예측된다(Cha, Hwang, \& Kim, 2019). 순 유형자 산의 비중(CAPEX)은 감가상각대상 자산을 자산총계로 나눈 값을 이용 하였다. 순 유형자산의 비중은 회계이익과 과세소득에 미치는 영향이 모두 존재하는 변수로 본 연구에서 이를 통제할 목적으로 포함하였다(P ark \& Jeon, 2008). 연구개발비(RSRV)는 기업의 연구개발비 비중을 가리 키며 연구개발비 비중이 높을수록 세제혜택에 따른 BTD에 미치는 영향 을 고려하고자 포함하였다. BETA는 체계적 위험이다. 연간 시장모형으 로 추정한 위험으로 이 값이 커질수록 BTD와의 관계는 양(+)으로 예측 된다(Cha \& Jin, 2017). VOL은 일별수익률의 표준편차로 분산이 커질수록 시장 위험이 증가하므로 이 값과 BTD 역시 양의 값이 사전적으로 예측 된다. 외국인 투자자 지분율(FOR)은 의결권이 있는 보통주 지분율을 이 용하였다.

외국인 투자자 지분율은 소유구조(ownership structure)를 대리하는 변 수로써 이 변수의 값이 증가할수록 경영자의 자의적인 의사결정을 감 시할 수 있다고 알려져 있다(Ahn. Shin, \& Chang, 2005). 따라서 외국인투 자자 지분율(FOR)과 BTD간의 관련성은 음(-)의 관계가 예측된다. BIG4는 감사인이 대형감사인이면 1 , 그렇지 않으면 0 의 지시변수이다. 감사인 이 대형감사인인 경우 상대적으로 더 높은 감사품질을 제공한다는 이 전 연구를 바탕으로 볼 때 종속변수인 BTD와 음(-)의 관계가 사전적으로 예측된다. 산업별 더미변수는 한국표준산업분류 중 중분류를 기준으로 포함하였다.

\section{3. 표본선정}

본 연구의 표본기간은 2003 년부터 2014 년까지이며 분석대상이 되는 자본시장은 유가증권시장 상장 기업이다. 이를 위하여 NICE 평가정보(주)의 데이터베이스인 KIS-VALUE 를 이용하여 본 연구에서
필요한 재무자료를 구했으며 앞서 언급한 바와 같이 분석기간은 2003 년부터 2014 년까지이나 데이터베이스에서 추출한 기간은 2001 년부터 2014 년까지의 기간이다. 이전의 연구방법론에 언급한 조작적 정의에 따라 필요한 자료를 확보할 수 있는 경우로 제한하여 결과적으로 분석에 사용된 기업-연도는 총 4,251 개이며 이에 대한 연도별 산업별 표본분포는 <Table 4>에 제시하였다. 분석에 이용하는 변수의 경우 극단 치에 의한 결과왜곡을 방지하고자 상하위 $1 \%$ 와 $99 \%$ 를 초과하는 경우 윈저화하여 극단 치가 결과에 미치는 영향을 상쇄하였다. 단, 지시변수나 자연로그를 취한 변수에는 적용하지 않았다. 연도별 표본분포는 해를 거듭할수록 크기가 커지는 것을 확인할 수 있었으며 제조업(C)의 경우 가장 많은 표본분포가 존재하였다. 실제 분석에서는 <Table 4>에 제시된 것과 같이 대분류로 이용하지 않고 중분류를 이용하였다.

Table 4: Samples Distribution

\begin{tabular}{|c|c|c|c|c|c|c|}
\hline year & $\mathbf{C}$ & $\mathbf{F}$ & $\mathbf{G}$ & $\mathbf{J}$ & $\mathbf{M}$ & Total \\
\hline 2003 & 143 & 13 & 11 & 0 & 36 & 203 \\
\hline 2004 & 217 & 17 & 14 & 2 & 42 & 292 \\
\hline 2005 & 236 & 20 & 18 & 3 & 43 & 320 \\
\hline 2006 & 246 & 19 & 23 & 3 & 44 & 335 \\
\hline 2007 & 268 & 19 & 25 & 3 & 42 & 357 \\
\hline 2008 & 270 & 20 & 26 & 3 & 38 & 357 \\
\hline 2009 & 276 & 21 & 25 & 5 & 37 & 364 \\
\hline 2010 & 287 & 19 & 26 & 6 & 34 & 372 \\
\hline 2011 & 301 & 13 & 28 & 6 & 37 & 385 \\
\hline 2012 & 309 & 13 & 31 & 12 & 39 & 404 \\
\hline 2013 & 316 & 16 & 44 & 10 & 38 & 424 \\
\hline 2014 & 330 & 14 & 45 & 11 & 38 & 438 \\
\hline Total & 3,199 & 204 & 316 & 64 & 468 & 4,251 \\
\hline
\end{tabular}

Note: C: Manufacturing, F: Construction, G: Wholesale and retail tra de, J:Information and communication, M: Service, Classification is $b$ y Korean Standard Industrial Classification

\section{4. 실증분석결과}

\section{1. 단변량분석}

본 연구에 사용된 주요변수들의 기술통계량과 상관관계분석결과를 <Table 5>와 <Table 6>에 제시하였다. 기술통계량을 제시한 <Table $5>$ 에는 평균(Mean), 최솟값(Min), 1 사분위수(25), 중위수(Mdn), 3 
사분위수(75), 최댓값(Max)순으로 제시하였다. 먼저, 회계이익과 과세소득의 차이는 평균이 0, 최댓값 0.32 , 최솟값이 0.69 로 나타났다. 표준편차가 0.08 을 갖는 것으로 나타나 표본 간의 BTD가 매우 큰 것을 알 수 있었다. 아울러 본 연구의 BTD 분포는 이전 유관연구의 결과와 유사하게 나타났다. 소수의 순위변수로 치환한 경우 중위수는 0.50 , 최솟값은 0 , 최댓값은 1 로 나타났다. 한편 본 연구의 양의 회계이익과 과세소득의 차이(PBTD)는 평균이 0.57 로 나타났다. 이는 표본의 약 $57 \%$ 가 양(+)의 BTD 를 보이는 것으로 볼 수 있다. 재량적 수익조정(DREV)과 같이 추정에 의한 경우에는 표본의 크기가 절반정도로 구분될 수 있으나 이는 개별 기업의 고유의 값이므로 비 대칭적인 값을 갖는다. 재량적 수익조정(DREV)은 평균이 0 , 최댓값은 0.14 , 최솟값은 -0.14 로 나타났다.

한편 통제변수의 경우 대체적으로 유관연구와 유사한 결과가 나타났다. 부채비율(ㄴV)은 평균이 약 $43 \%$, 최솟값이 $7 \%$ 에서 최댓값이 $87 \%$ 로 나타나 상장시장을 대상으로 한 연구와 결과가 유사하게 도출되었다(Cha \& Choi, 2020). 총 자산대비 순 유형자산의 비중(CAPEX)은 평균이 약 $18 \%$, 수익성(ROA)은 연평균 $3 \%$, 체계적 위험(BETA)은 약 0.76 으로 나타났다. 표본 중 감사인이 대형회계법인인 경우는 표본의 약 $55 \%$ 로 나타났다.

Table 5: Variables Definition

\begin{tabular}{|c|c|c|c|c|c|}
\hline Variable & Mean & S.D. & $\mathbf{2 5}$ & Mdn & $\mathbf{. 7 5}$ \\
\hline BTD & -0.00 & 0.08 & -0.02 & 0.00 & 0.02 \\
\hline FBTD & 050 & 0.29 & 0.25 & 050 & 0.75 \\
\hline PBTD & 057 & 0.50 & 0.00 & 1.00 & 1.00 \\
\hline DREV & -0.00 & 0.04 & -0.02 & -0.00 & 0.02 \\
\hline SIZE & 2657 & 1.45 & 2556 & 26.32 & 2731 \\
\hline LEV & 0.43 & 0.19 & 0.28 & 0.43 & 057 \\
\hline ROA & 0.03 & 0.13 & -0.04 & 0.06 & 0.12 \\
\hline BTM & 1.08 & 0.89 & 0.52 & 0.81 & 1.30 \\
\hline CAPEX & 0.18 & 0.13 & 0.08 & 0.15 & 0.24 \\
\hline RSRV & 0.03 & 0.06 & 0.00 & 0.01 & 0.04 \\
\hline BETA & 0.76 & 0.37 & 0.49 & 0.74 & 1.02 \\
\hline VOL & 0.48 & 0.18 & 0.35 & 0.45 & 0.57 \\
\hline FOR & 0.11 & 0.14 & 0.01 & 0.04 & 0.15 \\
\hline BIG4 & 055 & 0.50 & 0.00 & 1.00 & 1.00 \\
\hline
\end{tabular}

<Table 6>에 제시된 피어슨 상관관계는 두 변수 간의 단순한 상관관계를 나타낸 것이다. 간결한 결과 제시를 위하여 종속변수로 사용하였던 BTD 4 가지는 모두 이용하지 않고 연속변수인 BTD 의 경우만 이용하였다. 먼저 본 연구의 관심변수인 재량적 수익조정
측정치(DREV)와 BTD 의 관계를 통계적으로 유의한 양(+)의 관계(0.087)를 나타났다. 이는 재량적 수익조정이 증가할수록 BTD 가 같은 방향으로 증가함을 의미한다. 이외 통제변수와 종속변수(BTD)간의 관계는 기업규모(SZF), 수익성(ROA), 체계적 위험(BETA), 외국인투자자 지분율(FOR), 대형회계법인 감사인 여부(BIG4)가 유의한 양(+)의 관련성을, 부채비율(LV), 장부가치 대비 시장가치(BTM), 일별수익률의 표준편차(VOL)와 음(-)의 관련성을 보였다. 피어슨 상관관계분석 상 두 변수, 재량적 수익조정과 BTD 는 양(+)의 관련성을 보였으나 보다 강건한 결과를 도출하고자 다음 절에 다중회귀분석을 실시하고자 한다. 한편, 다중회귀분석에서 우려될 수 있는 다중공선성에 대한 문제는 분산팽창지수(MF)로 확인한 결과 전(全) 모형에서 모두 5 이하로 나타나는 바 다중공선성에 의한 영향은 문제되지 않는다고 판단하였다.

Table 6: Pearson Correlation

\begin{tabular}{|c|c|c|c|c|c|c|}
\hline & (1) & (2) & (3) & (4) & (5) & (6) \\
\hline & BTD & $\begin{array}{c}\text { DRE } \\
\text { V }\end{array}$ & SIZE & LEV & ROA & BTM \\
\hline$(1)$ & 1 & & & & & \\
\hline (2) & $0.09^{*}$ & 1 & & & & \\
\hline (3) & $0.15^{*}$ & $0.04 *$ & 1 & & & \\
\hline (4) & $-0.23 *$ & 0.01 & $0.10^{*}$ & 1 & & \\
\hline (5) & $0.17 *$ & $0.06^{*}$ & $0.04 *$ & 0.00 & 1 & \\
\hline (6) & $-0.04 *$ & 0.01 & $0.11 *$ & $0.22 *$ & $0.09 *$ & 1 \\
\hline (7) & -0.01 & -0.02 & $0.11 *$ & $0.11 *$ & 0.02 & $-0.03 *$ \\
\hline$(8)$ & 0.02 & 0 & $0.18^{*}$ & $-0.09 *$ & -0.02 & $0.10^{*}$ \\
\hline (9) & $0.03 *$ & 0.01 & $0.35^{*}$ & $0.17^{*}$ & $0.05^{*}$ & $0.15^{*}$ \\
\hline (10) & $-0.18^{*}$ & $-0.03 *$ & $-0.27 *$ & $0.29 *$ & $0.05^{*}$ & $0.18^{*}$ \\
\hline (11) & $0.08 *$ & -0.02 & $0.45^{*}$ & $-0.13^{*}$ & 0.01 & $0.16^{*}$ \\
\hline \multirow[t]{3}{*}{ (12) } & $0.10 *$ & 0.00 & $0.23^{*}$ & 0.02 & $0.07 *$ & 0.02 \\
\hline & (7) & (8) & (9) & (10) & (11) & (12) \\
\hline & $\begin{array}{c}\text { CAPE } \\
\mathbf{X} \\
\end{array}$ & RSRV & BETA & VOL & FOR & BIG4 \\
\hline (7) & 1 & & & & & \\
\hline$(8)$ & 0.00 & 1 & & & & \\
\hline (9) & $0.05^{*}$ & 0.03 & 1 & & & \\
\hline (10) & $-0.05^{*}$ & $-0.14 *$ & $0.35^{*}$ & 1 & & \\
\hline (11) & $0.05^{*}$ & $0.23^{*}$ & $0.10^{*}$ & $-0.19^{*}$ & 1 & \\
\hline (12) & $0.09^{*}$ & $0.11^{*}$ & $0.14^{*}$ & $0.05^{*}$ & $0.22^{*}$ & 1 \\
\hline
\end{tabular}

Notes: * indicate that the estimated coefficients are statistically signi ficant at $5 \%$ levels, respectively.

\section{2. 다중회귀분석}

<Table 7>에는 본 연구의 가설을 검증한 결과를 나타냈다. <Table 7>의 상단에는 본 연구의 모형을 제시하였고 모형(1)과 모형(2)은 모두 
종속변수의 차이에 의한 구분이다. 모형(1)의 경우 종속변수가 연속변수인 BTD 인 반면, 모형(2)의 경우 BTD 를 소수의 순위변수(FBTD)로 치환한 후의 결과를 제시하였다. 분석결과의 간결한 보고를 위해 산업별, 연도별 지시변수는 분석엔 포함하였으나 결과를 제시하지는 않았다. 즉, 아래의 <Table 7>는 산업별, 연도별 효과를 고려한 후의 결과이다. 표에 제시한 결과는 fim-year clustening 한 회귀분석으로 산출된 결과이다. 모형의 적합성을 가리키는 $\mathrm{F}$ 값은 모형(1)과 모형(2)에서 모두 $1 \%$ 수준에서 유의한 값이 도출되었으며 조정 결정계수(ad. R')의 경우 종속변수가 모형(1)의 경우 $15.1 \%$, 모형(2)의 경우 $6.6 \%$ 가 나타났다.

Table 7: Regression Result

\begin{tabular}{|c|c|c|c|c|}
\hline \multicolumn{5}{|c|}{$\begin{array}{c}\text { BTD }_{i, t+1}=\beta_{0}+\beta_{1} D_{R E V_{i, t}}+\beta_{2} \text { SIZE }_{i, t}+\beta_{3} L_{E V_{i, t}}+\beta_{4} \text { ROA }_{i, t}+ \\
\beta_{5} \text { BTM }_{i, t}+\beta_{6} C A P E X_{i, t}+\beta_{7} \text { RSRV }_{i, t}+\beta_{8} B E T A_{i, t}+\beta_{9} V O L_{i, t}+ \\
\beta_{10} F O R_{i, t}+\beta_{11} B I G 4_{i, t}+\beta_{12} \text { BETA }_{i, t}+\sum Y E A R+\sum K S I C+\varepsilon_{i, t}\end{array}$} \\
\hline & \multicolumn{2}{|c|}{ Model (1) } & \multicolumn{2}{|c|}{ Model(2) } \\
\hline & \multicolumn{2}{|c|}{ Dependent: BTD } & \multicolumn{2}{|c|}{ Dependent: FBTD } \\
\hline & Coef. & t-stats & Coef. & t-stats \\
\hline Constant & $-0.153^{*+\infty+\infty}$ & $(-4.21)$ & $0.445^{-0.46}$ & (3.41) \\
\hline DREV & $0.148^{\text {seper }}$ & (4.86) & $0.222^{*}$ & (2.03) \\
\hline SIZE & $0.008^{\text {kekpk }}$ & $(6.40)$ & 0.007 & (1.56) \\
\hline LEV & $-0.019^{k-1 . k x}$ & $(-14.62)$ & $-0.057^{\text {stok }}$ & $(-11.91)$ \\
\hline$R O A$ & $0.059^{\text {kiphe }}$ & (10.89) & $0.157^{* \text { kak }}$ & (8.16) \\
\hline$B T M$ & $0.004^{* *}$ & (2.33) & $0.035^{* * a k}$ & $(6.22)$ \\
\hline CAPEX & $-0.031^{\text {wede }}$ & $(-2.67)$ & -0.054 & $(-1.32)$ \\
\hline$R S R V$ & $-0.048^{* * *}$ & $(-2.12)$ & 0.015 & $(0.19)$ \\
\hline BETA & $0.890^{* * *}$ & (2.13) & $3.399^{* * *}$ & (2.26) \\
\hline$V O L$ & $-0.062^{\text {wowk }}$ & $(-6.42)$ & $-0.174^{* * * *}$. & $(-5.05)$ \\
\hline FOR & $-0.036^{\text {teat }}$ & $(-3.62)$ & $-0.078^{* k+k}$ & $(-2.15)$ \\
\hline$B I G 4$ & $0.008^{* * *}$ & $(2.47)$ & 0.016 & (1.45) \\
\hline$\sum K S I C$ & \multicolumn{2}{|c|}{ Included } & \multicolumn{2}{|c|}{ Included } \\
\hline$\sum Y E A R$ & \multicolumn{2}{|c|}{ Included } & \multicolumn{2}{|c|}{ Included } \\
\hline $\operatorname{adj} . R^{2}$ & \multicolumn{2}{|c|}{0.151} & \multicolumn{2}{|c|}{0.066} \\
\hline$F$ 값 & \multicolumn{2}{|c|}{$19.499^{* * * * *}$} & \multicolumn{2}{|c|}{$8.306^{* * * *}$} \\
\hline$N$ & \multicolumn{2}{|c|}{4,251} & \multicolumn{2}{|c|}{4,251} \\
\hline
\end{tabular}

Notes: $*, * *$ indicate that the estimated coefficients are statistically significant at $5 \%, 10 \%$ levels, respectively.

실증분석결과를 살펴보면, 모형 (1)의 경우 $1 \%$ 수준에서 유의한 양(+)의 값이 나타나 재량적 수익조정(DREV)이 증가할수록 회계이익과 과세소득의 차이(BTD)의 값이 커진다는 것을 확인할 수 있었다. 이는
재량적 수익조정의 측정치가 그간의 전통적인 이익조정의 측정치에 비해 보다 측정오차를 완화한 결과를 제시한다는 이전연구의 결과를 바탕으로 볼 때 재무보고 질이 악화될수록 BTD가 커진다고 해석할 수 있다. 한편, 통제변수의 경우 기업규모(SIZE), 수익성(ROA), 장부가치 대비 시장가치(BTM), 체계적 위험(BETA), 대형감사인 여부(BIG4)가 종속변수인 회계이익과 과세소득의 차이(BTD)와 양(+)의 관계를, 부채비율(LEV) 순유형자산의 비중(CAPEX), 연구개발비 비중(RSRV), 일별수익률의 표준편차(NOL), 외국인투자자 지분율(FOR)과는 음(-)의 관계가 나타났다. 기업규모가 클수록, 수익성이 높을수록, 성장성이 높을수록, 체계적 위험이 클수록 감사인이 대형 감사인인 경우 BTD 가 증가하는 한편 부채비율이 높을수록, 순유형자산의 비중이 높을수록, 일별수익률의 표준편차가 클수록 외국인투자자의 지분율이 높을수록 BTD 가 감소하였다.

BTD 를 소수의 순위변수로 측정한 결과인 모형(2)의 결과에서도 동일하게 유의한 값을 도출할 수 있었다. 즉, 재량적 수익조정(DREV)과 $\mathrm{FBTD}$ 간의 $5 \%$ 수준에서 통계적으로 유의한 값(회귀계수: $0222, \mathrm{t}$ 값: 2.03)이 관찰되었다. 다시 말해, 재량적 수익조정이 증가할수록 BTD 가 증가하는 것으로 나타났다. 통제변수의 경우 매출액 수익성(ROA), 장부가치 대비 시장가치(BTM), 체계적 위험(BEAA)과 양(+)의 관계를, 부채비율(LEV과 일별수익률의 표준편차(NOL), 외국인투자자 지분율(FOR)과 음(-)의 관계가 나타났다. 즉, 수익성이 높을수록 장부가치 대비 시장가치가 높을수록 체계적 위험이 높을수록 FBTD 가 증가하는 한편 부채비율이 높을수록 일별수익률의 표준편차가 클수록 외국인 투자자 지분율이 높을수록 FBTD 가 감소하였다. 이러한 결과는 모형(1)에 비해 다소 보수적인 결과를 갖는 것으로 나타났다.

$<$ Table 8>에는 양(+)의 BTD 를 갖는 경우(PBTD)와 큰 양(+)의 BTD 를 갖는 경우( $(\mathrm{PBTD})$, 그리고 큰 음(-)의 $\mathrm{BTD}$ 를 갖는 경우로 구분해 분석해 본 결과이다. 앞서 연구방법론에 제시한 바와 같이 종속변수가 모두 1 , 0 의 지시변수형태를 하므로 기업(fim)-연도(year)의 군집성(dustering)을 통제한 후의 logit 회귀분석결과를 제시한다. 결과제시는 앞선 제시방법과의 일관성을 위해 산업별 지시변수와 연도별 지시변수의 회귀계수와 $\mathrm{t}$ 값을 실제 분석에서는 포함하였으나 따로 제시하지는 않았다. 분석결과를 살펴보면, 모형(1)은 종속변수가 PBTD 인 경우 모형(2)은 LPBTD 인 경우이며 모형(3)은 LNBTD 의 결과이다. 즉, 모형(1)에서 모형(3)은 종속변수의 차이에 의한 구분이다. 앞선 분석과 달리 분석모형의 특성상 결정계수를 pseudo $R^{2}$ 로 보고하고 모형의 적합도 역시 $X^{2}$ 로 대체하여 제시하였다. 모형의 결정계수는 약 $6.8 \%$ 에서 $7 \%$ 로 나타났으며 모형의 적합성은 $1 \%$ 수준에서 통계적으로 유의하게 나타났다.

모형(1)의 관심변수인 재량적 수익조정(DREV)은 $5 \%$ 수준에서 통계적으로 유의한 양(+)의 값(Coef: 1.736, t-stat : 2.07)이 나타났다. 즉, 재량적 수익조정이 증가할수록 양(+)의 회계이익과 과세소득의 
차이(PBTD)를 보인다는 것이다. 경영자의 자의적인 의사결정이 개입될 때 회계이익과 과세소득의 차이가 양(+)의 값으로 커진다는 이전연구결과에 비추어 볼 때 재량적 수익조정 역시 음(-)에 방향보다는 양(+)에 방향으로의 영향이 더 존재함을 의미한다. 이러한 현상이 이익의 질이 낮다고 보이는 극단의 값(LPBTD)에 미치는 영향을 살펴보기 위해 실시한 모형(2)의 결과에서도 마찬가지로 $5 \%$ 수준에서 유의한 양(+)의 값(Coef : 2.043 , t-stat : 2.43)이 도출되었다. 이는 재량적 수익조정이 증가하면 큰 양(+)의 회계이익과 과세소득 차이(LPBTD)에 속할 가능성이 나머지 $75 \%$ 의 회계이익과 과세소득의 차이에 비해 유의하다는 것을 의미한다.

Table 8: Additional Test

\begin{tabular}{|c|c|c|c|c|c|c|}
\hline \multicolumn{7}{|c|}{ 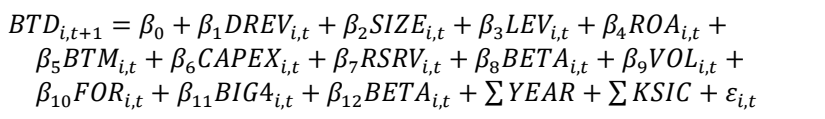 } \\
\hline & \multicolumn{2}{|c|}{ Model (1) } & \multicolumn{2}{|c|}{ Model (2) } & \multicolumn{2}{|c|}{ Model (3) } \\
\hline & \multicolumn{2}{|c|}{$\begin{array}{c}\text { Dependent: PBT } \\
\text { D }\end{array}$} & \multicolumn{2}{|c|}{$\begin{array}{c}\text { Dependent: LPB } \\
\text { TD }\end{array}$} & \multicolumn{2}{|c|}{$\begin{array}{c}\text { Dependent: LNB } \\
\text { TD }\end{array}$} \\
\hline & Coef. & t-stats & Coef. & t-stats & Coef. & t-stats \\
\hline Intercept & 0.48 & $(0.55)$ & 0.59 & $(0.68)$ & $2.69^{* * *}$ & $(2.20)$ \\
\hline DREV & $1.74^{* * *}$ & (2.07) & $2.04^{* *}$ & (2.43) & $-1.91^{*}$ & $(-1.78)$ \\
\hline SIZE & 0.02 & $(0.55)$ & -0.01 & $(-0.27)$ & $-0.21^{* * *}$ & $(-4.63)$ \\
\hline LEV & $-0.37^{* * *}$ & $(-9.07)$ & $-0.35^{* * *}$ & $(-8.53)$ & $0.50^{* * * *}$ & (10.86) \\
\hline ROA & $0.99^{* * *}$ & (6.45) & $0.96^{* * *}$ & (6.36) & $-1.44^{* * *}$ & $(-6.96)$ \\
\hline BTM & $0.22^{* * * *}$ & (4.94) & $0.27^{* * *}$ & (5.96) & $-0.13^{* *}$ & $(-2.32)$ \\
\hline CAPEX & -0.43 & $(-1.38)$ & -0.32 & $(-1.02)$ & $1.60^{* * *}$ & (3.88) \\
\hline RSRV & 0.05 & $(0.08)$ & -0.05 & $(-0.09)$ & -0.13 & $(-0.15)$ \\
\hline BETA & 8.85 & $(0.77)$ & 11.24 & $(0.99)$ & -14.92 & $(-1.00)$ \\
\hline VOL & $-1.43^{* * * *}$ & $(-5.46)$ & $-1.25^{* * *}$ & $(-4.75)$ & $1.79^{* * * *}$ & (5.55) \\
\hline FOR & $-0.50^{*}$ & $(-1.83)$ & $-0.46^{*}$ & $(-1.70)$ & $0.63^{*}$ & (1.69) \\
\hline BIG4 & 0.11 & $(1.27)$ & $0.18^{* *}$ & (2.11) & -0.04 & $(-0.32)$ \\
\hline$\sum$ KSIC & \multicolumn{2}{|c|}{ Included } & \multicolumn{2}{|c|}{ Included } & \multicolumn{2}{|c|}{ Included } \\
\hline$\sum$ YEAR & \multicolumn{2}{|c|}{ Included } & \multicolumn{2}{|c|}{ Included } & \multicolumn{2}{|c|}{ Included } \\
\hline pseudo $\mathrm{R}^{2}$ & \multicolumn{2}{|c|}{0.068} & \multicolumn{2}{|c|}{0.070} & \multicolumn{2}{|c|}{0.133} \\
\hline$x^{2}$ & \multicolumn{2}{|c|}{$393.356 * * *$} & \multicolumn{2}{|c|}{$411.733 * * *$} & \multicolumn{2}{|c|}{$504.708^{* * * *}$} \\
\hline $\mathrm{N}$ & \multicolumn{2}{|c|}{4,251} & \multicolumn{2}{|c|}{4,251} & \multicolumn{2}{|c|}{4,251} \\
\hline
\end{tabular}

Notes: $*, * *$ indicate that the estimated coefficients are statistically significant at 5\%,10\% levels, respectively

종속변수를 LNBTD 로 분석한 경우 $10 \%$ 수준에서 통계적으로 유의한 음(-)의 값이 도출되었다. 이는 재량적 수익조정을 할수록 하위 $25 \%$ 의
BTD 에 속하지 않을 가능성이 매우 높음을 의미한다. LNBTD 의 경우 경영자의 보수적 회계처리에 의한 현상으로 보거나 LNBTD 의 경우 신용평가사에서 정보위험으로 간주하지 않는다는 것을 비추어 볼 때 상대적으로 재량적 수익조정이 덜 이루어짐을 의미한다.

\section{5. 결론 및 한계점}

본 연구는 재량적 수익조정과 BTD 를 실증적으로 검토해본 연구이다. 재량적 수익조정은 경영자의 수익항목을 통한 이익조정을 측정하는 방법으로써 국내자본시장을 대상으로 그 유용성에 대한 연구가 아직 미진하다. 경영자의 수익을 통한 이익조정이 조세회피로 간주되는 BTD 를 이용해 유용성을 확보하고 그간 계량경제학적 오류를 갖는 것으로 알려진 재량적 발생액의 대체적인 측정치로써 유용성을 갖는지 확인해볼 수 있다는 점에서 선행연구와 차별점이 존재한다. 이를 확인하고자 2003 년부터 2014 년까지 11 년간의 유가증권시장 상장기업을 대상으로 검증한 결과 재량적 수익조정이 증가할수록 BTD 가 증가하는 양의 관련성을 갖는 것으로 나타났으며 이러한 결과는 BTD 를 순위변수로 바꿔보거나 양(+)의 값만 갖는 경우(PBTD), 큰 양(+)의 값을 갖는 경우(PBTD) 모두 같은 결과를 도출할 수 있었다. 그러나 큰 음(-)의 값을 갖는 경우(LNBTD)에는 음(-)의 관계가 나타났다. 종합하면 재량적 수익조정 역시 회계이익과 과세소득의 차이를 크게 만드는 하나의 지표로써 활용될 수 있으며 재량적 수익조정이 회계정보 품질에 미친다는 국내자본시장을 대상으로 한 최초의 연구로써 의의를 갖는다. 또한, 본 연구의 결과는 향후 이익조정의 연구에 있어서 재량적 발생액과 실물활동을 통한 이익조정의 측정치뿐만 아니라 재량적 수익활동 또한 활발히 연구되어야 할 분야임을 의미한다. 그러나 이러한 이점에도 불구하고 추정에 의한 측정치가 갖는 측정오차 문제는 여전히 한계점으로 나타나며 아울러 본 연구에서 미처 고려하지 못한 변수가 연구결과에 영향을 미칠 수 있다는 점에서 유의한 해석이 요구되며 추가적인 후속연구가 필요하다. 특히, 조세회피와 이익조정의 특성을 모두 가지고 있는 BTD 의 경우 향후 연구에서는 어떠한 특성에 보다 강한 관련성을 가지는 지 차별적 속성을 살펴볼 필요가 있다.

\section{References}

Ahn, Y. Y., Shin, Y. H., \& Chang, J. H. (2005). The relationship between the foreign investor and information asymmetry, Korean Accounting Review, 30(4), 109-131.

Aziz, J., Ji, S. H., \& Lee, K. B. (2019). A study on the relevance between book-tax difference and earnings information, Tax Accounting Research, 59, 117-135.

Becker, C. L., DeFond, M. L., \& Jiambalvo, J. (1998). The effect 
of audit quality on earnings management. Contemporary Accounting Research, 15(1), 1-24.

Blaylock, B., Shevlin, T., \& Wilson, R. J. (2011). Tax avoidance, large positive temporary book-tax differences, and earnings persistence. The Accounting Review, 87(1), 91-120.

Cha, S. K., \& Choi, H. J. (2020). The impact of overvaluation on analyst's forecasting errors. The Journal of Industrial Distribution \& Business, 11(1), 39-47.

Cha, S. K., \& Jin, S. H. (2017). Market Concentration and Tax Avoidance, Tax and Accounting Review, 6(1), 177-211.

Cha, S. K., \& Park, M. H. (2020). The Empirical Study of Relationship between Product Market Competition Structure and Overvaluation, Journal of Distribution Science, 18(2), 99108.

Cha, S. K., Hwang S. P., \& Kim, Y. B. (2019) Business Strategy and Overvaluation: Evidence from Korea, The Journal of Asian Finance, Economics and Business, 6(4), 83-90.

Cho, Y. E., Choi, M. H., \& Lee, J. S. (2011). Book-tax differences, earnings management, and tax avoidance, Accounting Information Review, 29(1), 231-260.

Chun, H. M., \& Shim, J. Y. (2017), A comparison of Investors' and Analyst's Biases in interpreting book-tax difference: Evidence from Korean Stock Market, Global Business and Finance Review, 22(2), 16-33.

Crabtree, A., \& Maher, J. J. (2009). The influence of differences in taxable income and book income on the bond credit market. Journal of the American Taxation Association, 31(1), 75-99.

Dechow, P. M., \& Dichev, I. D. (2002). The quality of accruals and earnings: The role of accrual estimation errors. The Accounting Review, 77(s-1), 35-59.

Dechow, P. M., \& Schrand, C. M. (2004). Earnings quality. CFA Institute, U.S

Dechow, P. M., Sloan, R. G., \& Sweeney, A. P. (1995). Detecting earnings management. The Accounting Review, 70(2), 193-225.

Hwang, J. S. (2012). The effect of corporate governance on the relations among book-tax differences and earnings persistence, Korean International Accounting Review, 43, 123-146.
Jackson, M. (2015). Book-tax differences and future earnings changes. The Journal of the American Taxation Association, 37(2), 49-73.

Jones, J. J. (1991). Earnings management during import relief investigations. Journal of Accounting Research, 29(2), 193228.

Kothari, S. P., Leone, A. J., \& Wasley, C. E. (2005). Performance matched discretionary accrual measures. Journal of Accounting and Economics, 39(1), 163-197.

Lee, K. B., Ji, S. H., Ryu, Y. R., \& Kim, S. J. (2014). Firm governance and the volatility of book-tax difference, Journal of Finance and Accounting Information, 14(3), 21-38.

Lev, B., \& Nissim, D. (2004). Taxable income, future earnings, and equity values. The Accounting Review, 79(4), 1039-1074.

Oh, K. W., \& Ki, E. S. (2020). The Effect of Tax-Related Information on Pre-Tax Income Forecast and Value Relevance, The Journal of Asian Finance, Economics and Business, 7(1), 81-90.

Park, J. I., \& Jeon, K. A. (2008). The effect of audit quality on book-tax differences, Korean Accounting Review, 33(2), 65109.

Park, J. I., \& Yoon, S. R. (2014). Empirical evidence on the relationship between discretionary accruals and cost of debt, Korean Accounting Review, 39(3), 359-410.

Park, J. I., Ki, E. S., \& Kwon, S. Y. (2014). A review and some now evidence on the effect of boo-tax differences on bond rating, Korean Accounting Review, 39(3), 1-55.

Plesko, G. A. (2007). Estimates of the magnitude of financial and tax reporting conflicts, Proceedings of National Bureau of Economic Research.1-58

Roychowdhury, S. (2006). Earnings management through real activities manipulation. Journal of Accounting and Economics, 42(3), 335-370.

Stubben, S. R. (2010). Discretionary revenues as a measure of earnings management. The Accounting Review, 85(2), 695-717.

Turner, L. E., \& Weirich, T. R. (2006). A closer look at financial statement restatements. The CPA Journal, 76(12), 12-23 